\title{
Chapter 19 \\ Income Inequality and Economic Segregation in Los Angeles from 1980 to 2010
}

\author{
John R. Hipp and Jae Hong Kim
}

\begin{abstract}
Rising income inequality is a critical problem in both the global North and South. In the United States, the Gini coefficient measuring nationwide income inequality rose from 0.403 in 1980 to 0.480 in 2014 (US Census), and residential segregation by income has increasingly occurred in many metropolitan regions and is particularly reflected in the spatial separation of the wealthiest households. This chapter focuses on the change in the level of income inequality in the Los Angeles region since 1980 and how it is related to changes in residential segregation between economic groups over that same time period. We use data from the US Census collected in 1980, 1990, 2000, and 2010. We measure residential segregation between economic groups based on occupational structure, and measure 'neighbourhoods' using Census tracts: these are units defined by the US Census and typically average about 4,000 residents. The overall level of inequality in the region is measured at each decade point using the Gini coefficient for household income. Maps demonstrate where different socioeconomic status groups have tended to locate and how economic segregation has changed in Los Angeles over this time period. We also assess the extent to which changes in inequality are related to changes in economic segregation over the last four and a half decades.
\end{abstract}

Keywords Neighbourhoods $\cdot$ Economic segregation $\cdot$ Long-term trends

Electronic supplementary material The online version of this chapter (https://doi.org/10.1007/978-3-030-64569-4_19) contains supplementary material, which is available to authorized users.

J. R. Hipp (凶)

Department of Criminology, Law and Society, Social Ecology II, University of California, Irvine, CA 3311, USA

e-mail: john.hipp@UCI.edu

Department of Sociology, University of California, Irvine, USA

J. H. Kim

Department of Urban Planning and Public Policy, University of California, Irvine, USA

(C) The Author(s) 2021

M. van Ham et al. (eds.), Urban Socio-Economic Segregation and Income Inequality,

The Urban Book Series, https://doi.org/10.1007/978-3-030-64569-4_19 


\subsection{Introduction}

An upward trajectory of economic inequality has been quite apparent around the world, although what has caused this trend would vary widely across countries, and so does the response chosen to address it. In the United States, the Gini coefficient measuring income inequality had begun to rise rapidly since the 1980s and increased every decade, despite yearly ups and downs. ${ }^{1}$ Nationwide, this (uncomfortable) reality has received extensive media coverage, often highlighting what percentage of the aggregated income growth has been taken by the top $1 \%$ and how the income (or wealth) concentration has been accelerated in recent decades. Much attention has also been paid in academic and policy circles to ways to curb this trend of 'the fading American Dream' (Chetty et al. 2017) and promote intergenerational economic mobility.

The rising economic inequality is not an aspatial phenomenon. There is substantial variation across regions, and it has been reported that ' $[\mathrm{t}]$ he rise in inequality experienced in the United States over the past four-plus decades is not just a story of those on Wall Street, in Hollywood, or in the Silicon Valley reaping outsized rewards, ... [and that] rising inequality and increases in top 1 percent incomes affect every part of the U.S.' (Sommeiller and Price 2018: p. 16). Furthermore, some recent studies have suggested that the rising inequality can take the form of a higher level of residential segregation between economic groups (economic segregation from hereafter) within a region, especially the separation of wealthier household groups from the remainder, which would further reinforce the increasing trend of inequality (see, e.g., Reardon and Bischoff 2011; Scarpa 2016). Such a reciprocal interaction between inequality and segregation would be particularly problematic when resource allocation and land-use decisions are not made in favour of disadvantaged groups or communities. In such circumstances, the vicious cycle can persist and create a significant disparity in access to jobs or other essential amenities/opportunities.

Yet, our understanding of these critical mechanisms is far from complete. As mentioned above, increasing inequality is an indisputable reality in the United States (or even worldwide). However, a question is whether this apparent macro change has played out differently across various metropolitan areas in the US. Little is known about the various ways in which economic groups are residentially segregated in contemporary cities or larger metropolitan areas along with rising inequality. Moreover, there has been a dearth of comparative work that would enable us to identify commonalities or capture (subtle) differences between cities or regions around the world.

This chapter, combined with other contributions in the book, attempts to fill this gap. More specifically, here consideration is given to Los Angeles (and its vicinity), which is unique in many ways but presents some important representative qualities of post-industrial large metropolises. Materials presented in this chapter were produced

\footnotetext{
${ }^{1}$ For more detailed information, see US Census Historical Income Tables: Income Inequality, available at https://www.census.gov/data/tables/time-series/demo/income-poverty/historical-incomeinequality.html.
} 
using an occupational classification scheme to make the analysis comparable to other case studies in the volume. The present occupation-oriented analysis was also expected to provide some fresh insights into the complex process that underlies the study region's segregation dynamics that would not be fully captured by traditional income-oriented approaches.

\subsection{Background}

The Los Angeles region provides an interesting case to study the spatial dynamics of inequality and segregation, given that studies have frequently pointed to its spatial layout as differing from the traditional monocentric development. Instead, it has been described as a polycentric region where an increasing number of employment subcenters have emerged (Kane et al. 2018). This region is the quintessential example of what is referred to as a member of the Sunbelt part of the country, and as such, exemplifies much of the post-World War II development in the United States in that it is a car culture built around roadways and highways, along with a relative lack of public transportation.

These characteristics of the Los Angeles region have been constructed through multiple waves of population and employment decentralisation over the history of its growth. While the City of Los Angeles grew most rapidly in the late nineteenth century through the 1930s, the entire metropolitan region has continued to expand dramatically. An early form of the suburban expansion occurred partly in the form of upper and middle-class flight from the core city, as observed in many other US metropolises, resulting in massive development in Orange County during the midtwentieth century (Note: Orange County's population increased more than ten times from 130 thousand to 1.42 million between 1940 and 1970. Currently, it is the sixth-most populous county in the nation with a population of over 3 million). In the late-twentieth century, the growth was headed toward inland areas, specifically Riverside and San Bernardino counties, where new housing units were provided at much more affordable rates, although job opportunities were relatively scarce there. More recently, there has been increasing evidence of inner-city gentrification and associated poverty suburbanisation (Tong and Kim 2019), but new development in remote locations has continued (Hipp et al. 2014). We display key features of the region in Fig. 19.1.

Much of the new development has taken place in the form of single-family housing construction. While the housing stock has diversified in the region, lowdensity residential development remains common, particularly in remote locations. The percentage of owner-occupied housing units, however, has not increased substantially over the last three decades. Despite the growing decentralisation of households, the overall percentage has remained around 54\%, while the level of homeownership varies across counties, ranging from $47 \%$ (Los Angeles County) to 68\% (Riverside County) in 2010. 


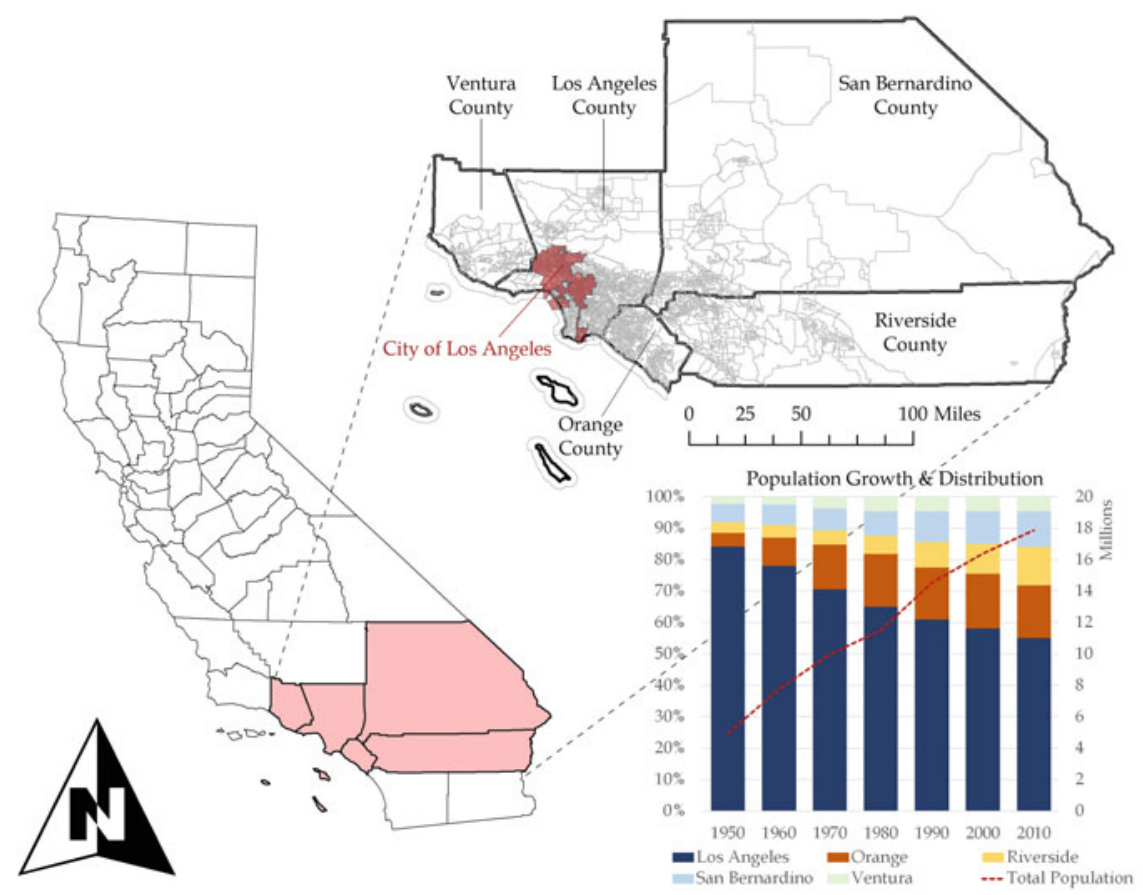

Fig. 19.1 Study region

Along with the expansion, there has been a proliferation of newly incorporated cities in the region, making it politically fragmented, since the 1950s. Most notably, in the state of California, '[t]he Lakewood Plan made incorporation cheaper and easier by allowing cities to contract for services with county governments. The Bradley Burns Act created fiscal incentives for incorporation by permitting California cities to capture a portion of the state sales tax. Local Agency Formation Commissions (LAFCOs) established the first statewide standards for incorporation. Finally, Proposition 13 incentivised municipal incorporation by allowing communities to capture sales tax and other revenue without fear of higher property taxes. Together, these reforms created fiscal incentives for incorporation that were hard for many communities to resist' (Hogen-Esch 2011: p. 7).

The newly incorporated places have surrounded existing localities, limiting their ability to expand geographically and achieve a critical mass for fiscal efficiency and other goals (Kim et al. 2018). Furthermore, this fragmented structure of governance has profound implications for the working of the metropolitan region, shaping the behaviour of both public and private sectors (Kim and Jurey 2013). Political fragmentation has been viewed as a cause of sprawl (Byun and Esparza 2005; Carruthers 2003; Ulfarsson and Carruthers 2006), although no single factor can fully explain the Los Angeles region's complex spatial structure. Fragmented local growth controls have 
pushed development out and made it particularly difficult to construct higher-density affordable housing units where the demand has arisen (Levine 1999).

In this light, it is not surprising that common interest developments (CIDs), including gated communities and condominiums, are prevalent in the Los Angeles metropolitan region. According to Sanchez et al. (2005), providing useful estimates based on the 2001 American Housing Survey data, a considerable percentage of households in the region reported that they lived in walled $(18.2 \%)$ or accesscontrolled $(11.7 \%)$ communities. Such types of housing developments are even more popular in new development projects, producing increased social segregation (Le Goix 2005). Fragmented local governments have been in favour of CIDs, which would allow them to 'acquire new property tax payers without having to extend to them the full panoply of municipal services, ... [and] some municipal governments have begun to virtually require that new housing construction consist of CIDs' (McKenzie 2003: p. 207).

These structural characteristics have also created various forms of isolation, even though there have been growing efforts to promote mixing in multiple dimensions (Hipp et al. 2017b). While the conventional spatial mismatch hypothesis does not fit well in the case of Los Angeles (Blumenberg and Manville 2004), a recent study has shown that job accessibility of inner-city residents has declined significantly in the region ( $\mathrm{Hu} 2015)$. Other forms of barriers have also existed, making it difficult to connect job opportunities to welfare recipients who are supposed to move from welfare to work in the post-1996 welfare reform era in the United States (Ong and Blumenberg 1998). It is not uncommon that workers commute across city or county borders in this large metropolitan area. The following empirical analysis shows how different groups of workers were spatially distributed and in what ways the spatial distributions have changed over time, based on their place of residence, as opposed to where their jobs were located.

Thus, although this is a single region, there are differences across the five counties in the region in various ways. These counties have different spatial patterns of amenities and jobs. The density of Los Angeles County can be seen in that its housing units have many more amenities within one mile of them (measuring various types of amenities such as retail, restaurants, parks, etc.) than the other counties; housing units in Orange County have the next most amenities nearby, with the other three counties having far fewer (Kane et al. 2017: 25). There is also more job density in Los Angeles county compared to the others: the downtown of Los Angeles city has long been a business hub (Kane et al. 2016), and the west side of Los Angeles also has a high jobs/housing relationship (Hipp et al. 2017a). In Orange County, the Irvine area serves as a high jobs/housing location, whereas the Inland Empire counties have less evidence of such jobs/housing locations (Hipp et al. 2017a). 


\subsection{Data and Methods}

\subsubsection{Data}

Our study area is the Los Angeles area, which is defined as the five-county Southern California metropolitan region, including Los Angeles, Orange, Riverside, San Bernardino and Ventura counties. For this large metropolitan region, we used census tracts as the unit of analysis to construct a temporally comparable neighbourhoodlevel dataset. We harmonised the tracts to 2010 boundaries based on populationweighted apportioning as defined by the US Census Master Area Reference Files. We used US Census data for the earlier waves, and used the American Community Survey 5-year estimates for the most recent decade (we used the 2008-12 data given that it is centred on 2010) to construct our dataset of 3,892 tracts with at least 100 population in 2010 .

To assess the socioeconomic status of the neighbourhoods in the region, in addition to the occupation measures, we created two other measures. One is a measure of the average household income of residents in the tract. The second is a measure of education level in the tract, and is captured by the percent of residents with at least a bachelor's degree.

\subsubsection{Methods}

A challenge is to define consistent categories of occupations over time. We used the ISO definitions for defining categories. We, therefore, classified nine categories of occupations, one of which-agriculture, forestry, and fishery workers-we excluded from analyses given the small proportion constituted by this group in this urban area. The categories are: (1) managers; (2) professionals; (3) technicians and associated professionals; (4) clerical support workers; (5) service and sales workers; (6) agriculture, forestry, and fishery workers; (7) craft and related trades workers; (8) plant and machine operators and assemblers; (9) elementary occupations. We describe how we classified the occupation codes defined by the US Census for each decade into each of these categories in Appendix Table A1 (available online).

We also constructed a measure of the degree of occupation mixing in neighbourhoods with a Herfindahl Index of the nine occupation codes just described. The measure is a sum of squares of the proportion of residents in a tract in each of the occupation categories, and then is subtracted from 1 to make it a measure of heterogeneity. The theoretical range is from 0 to 0.8742 . 


\subsection{Results}

\subsubsection{General Trends in Occupation Groups Over Time}

We begin by describing the socioeconomic status of the five counties in this region. Orange and Ventura Counties are the two wealthiest counties in the region with the highest average income and education levels, whereas Riverside and San Bernardino Counties are the two counties from the Inland Empire (IE) — which tends to be blue-collar - and consistently show the lowest average income and lowest levels of education. Los Angeles County, the largest county in the region, is between these two extremes based on socioeconomic status. Although Ventura County is closer to Los Angeles County for average education level, they are close to Orange County for average household income.

We next describe the change in household income inequality in the region overall, as well as across the five counties in the region, for our study period. ${ }^{2}$ The general upward trend in the level of inequality in the region has closely tracked the trend for Los Angeles County, the largest county in the region. The Gini coefficient for household income in the region has gone from 0.415 in 1980 to 0.43 in 1990 to 0.455 in 2000 before slightly falling to 0.449 by 2010 . Los Angeles County has paralleled this with systematically higher Gini values, and peaked at 0.474 in 2000 . The two Inland Empire (IE) Counties of Riverside and San Bernardino have very similar income inequality levels in 2010 , but took very different paths to that point. Whereas Riverside County had the second-highest level of income inequality in the region in 1980, inequality has only slightly increased over the time period in this County. In contrast, San Bernardino County has gone from relatively low-income inequality in 1980 (0.382) to steadily increasing such that they have nearly caught Riverside County by $2010(0.421)$. Finally, the two more wealthy counties are Orange and Ventura, and although they started with the lowest levels of inequality in the region in 1980 (0.37 and 0.38), they have both experienced quite steady increases over the entire study period such that Orange County has slightly higher income inequality than the two IE counties by 2010 .

Turning to the occupation structure of the region, Fig. 19.2 provides this information for the tracts in the region. We see that the percentage of professional employees in the region has increased dramatically since 1990 . Whereas $12 \%$ of employees were in professional occupations in 1980, this increased slightly to $13 \%$ in 1990 , and then jumped to $22 \%$ in 2000 and $28 \%$ in 2010 . This trend is clearly reflected in Fig. 19.3, which shows seven distinct types of neighbourhoods using a classification

\footnotetext{
${ }^{2}$ We computed the Gini coefficient for the region, as well as for each of the five counties, based on binned income data. Thus, we summed up the number of persons in each of the income bins for a particular decade, and then used the RPME ado package for Stata created by Paul T. von Hippel and Daniel A. Powers. It adjusts for the binned nature of the data, and uses an assumed Pareto distribution to handle the top-coded bin. There were 17 income bins in 1980, 25 bins in 1990, and 16 bins in 2000 and 2010.
} 

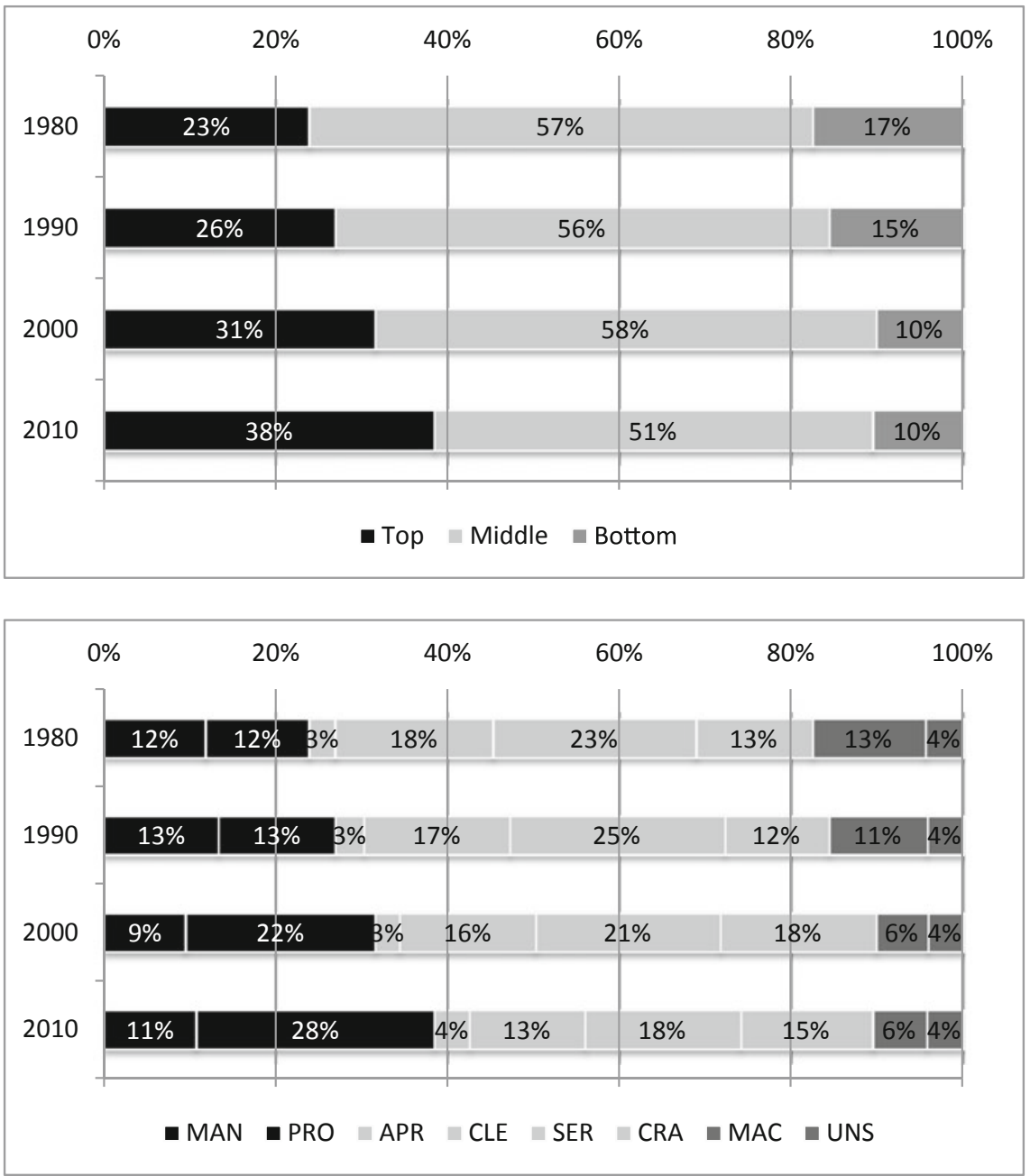

Fig. 19.2 Percentages of occupation classes in tracts in Southern California from 1980 to 2010

scheme provided by (Marcińczak et al. 2015). ${ }^{3}$ As demonstrated in the map, High SES neighbourhoods have expanded over time along with the rise of professional occupations in the region. The number of High SES neighbourhoods (having over $50 \%$ of managers or professional occupations) increased from 121 in 1980 to 1150

\footnotetext{
${ }^{3}$ Given that the original classification scheme does not cover all possibilities, we have expanded the definitions of the following three categories: High SES neighborhoods, Low SES neighborhoods, and Middle SES neighborhoods. Specifically, if one of the three groups accounted for over $50 \%$ of the total workers living in a neighborhood, the neighborhood was classified into one of the three categories.
} 


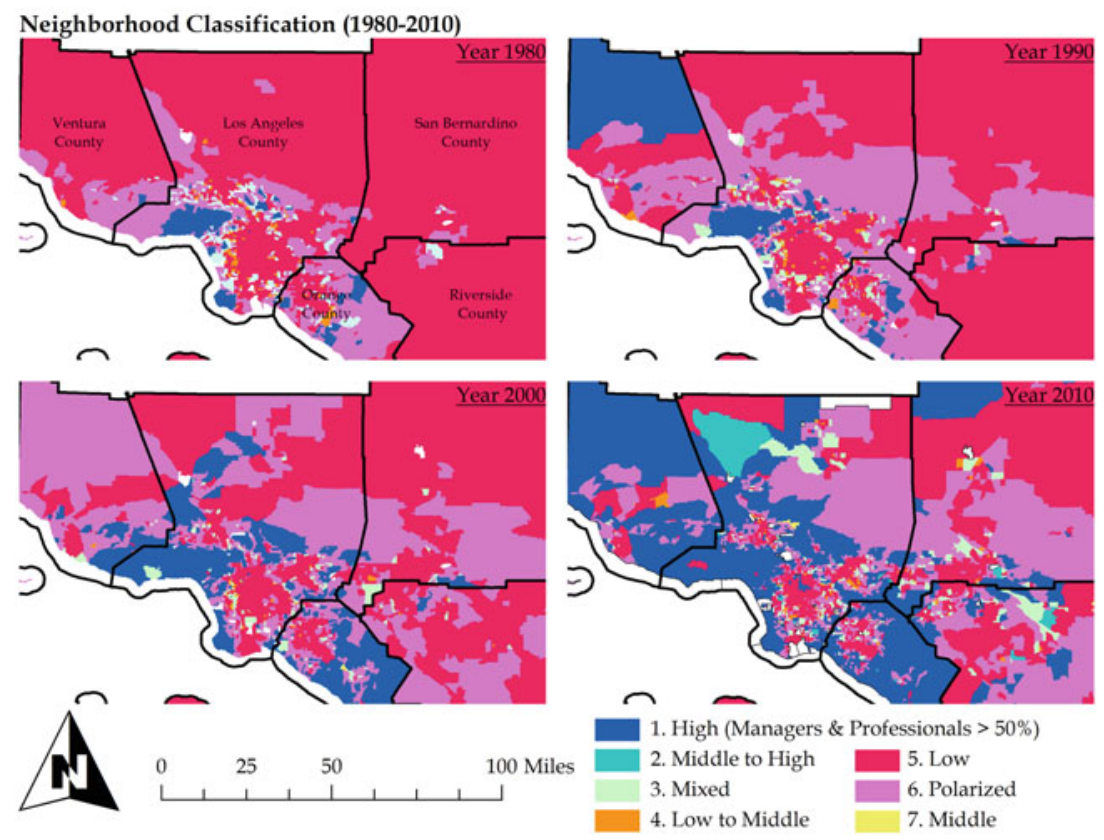

Fig. 19.3 Neighbourhood types in the Los Angeles region, 1980-2010

in 2010, although it has not surpassed that of the most dominant category in the region: Low SES neighbourhoods. In contrast, our study area turned out to have a much smaller number of Middle to high SES neighbourhoods and Middle SES neighbourhoods.

The percentage of workers classified as craft or related trades has shown a modest increase over this period, going from $13 \%$ in 1980 to $18 \%$ in 2000 before declining in recent years. The percentage of service and sales workers, clerical support workers, and plant and machine operators have all shown declines over the study period. It is also notable that the measure of occupational heterogeneity at the neighbourhood level has consistently declined over the study period, which is indirect evidence of increasing occupational segregation during this time period.

We also broke down the change in occupation structure across counties in the region over this study period. For several of the occupation categories, the counties followed similar trajectories. However, we highlight three particularly interesting patterns. First, whereas professional occupations have shown a general growth across all counties in the region, such jobs were relatively less present in the Inland Empire counties in 1980, and their growth has lagged behind that of the rest of the region since then. Whereas in 1980, about $10 \%$ of the jobs were constituted by professional occupations in the Inland Empire counties, the percentage was $14 \%$ in relatively wealthy Orange County. But by 2010, whereas the Inland Empire counties had increased to $23 \%$ professional occupations, in Orange County this had grown to $31 \%$. Ventura and 
Los Angeles Counties also exhibited greater growth in professional jobs compared to the IE counties. Second, there is also a notable change in the distribution of technicians, as the IE counties had the lowest percentage of such workers in 1980, but have experienced a steady relative increase at the same time that the proportion of such workers has stagnated in the other counties. By the 2000s, the IE counties had a much larger percentage of technicians compared to the other counties in the region. Third, although the relative presence of plant and machine operators has decreased across the region, the decrease was sharpest in Los Angeles County. Whereas in LA County, plant and machine operators constituted almost $15 \%$ of workers in 1980, this had been more than cut in half by the 2000s. The IE counties experienced a smaller decrease, and by the 2000s have a larger presence of plant and machine operators compared to LA County.

We also wished to assess the types of neighbourhoods that members of these different occupation groups live in. Note that this is different than focusing on the socioeconomic status of individual members of these occupations; rather, we are interested in characterising the socioeconomic status of the neighbourhoods that members of these occupation groups tend to live in. We did this by computing the correlation between the percentage of a tract that is composed of a particular occupation category and two key measures: the average household income in the tract, and the occupational heterogeneity in the tract. Table 19.1 displays the results, and the top panel shows the correlations with average household income. As expected, the strongest positive correlations with average household income in the tract occur for tracts with a higher proportion of manager or professional occupation workers. The third highest correlation in 1980 was with technicians and associated professionals, though this correlation weakened by 2010 and became similar to that for service and sales workers. Whereas in 1980, plant and machine operators lived in tracts with the lowest average household income, by 2010, this had shifted and craft and related trades workers lived in tracts with the lowest average household income.

In the bottom panel of Table 19.1, we show the correlation of the percent of various occupation groups in a tract with the occupational heterogeneity, which gives a sense of the extent to which members of various occupation groups live in neighbourhoods with a high degree of occupation mixing. In 1980, craft and related trades workers lived in neighbourhoods with the highest level of occupation mixing, and this level of mixing has remained relatively constant over the study period. On the other hand, whereas plant and machine operators in 1980 and 1990 tended to live in neighbourhoods with average levels of occupation mixing since 2000, they have lived in neighbourhoods with the highest levels of occupation mixing. At the other extreme, whereas service and sales workers lived in the most homogeneous occupation mixing neighbourhoods in 1980 and 1990, they have been in neighbourhoods with average levels of mixing since 2000. The level of mixing in the neighbourhoods of the highest occupation groups has consistently declined over the study period, especially for professional workers and especially since 2010 . 
19 Income Inequality and Economic Segregation in Los Angeles from $1980 \ldots$

Table 19.1 Correlation of percent in occupations with income and occupational heterogeneity

\begin{tabular}{|c|c|c|c|c|}
\hline & \multicolumn{4}{|c|}{ Correlation with average household income } \\
\hline & 1980 & 1990 & 2000 & 2010 \\
\hline Managers & 0.76 & 0.75 & 0.76 & 0.71 \\
\hline Professionals & 0.68 & 0.71 & 0.67 & 0.62 \\
\hline $\begin{array}{l}\text { Technicians and associate } \\
\text { professionals }\end{array}$ & 0.12 & 0.14 & -0.29 & -0.17 \\
\hline Clerical support workers & -0.18 & -0.19 & -0.28 & -0.33 \\
\hline Service and sales workers & -0.02 & -0.09 & -0.05 & -0.16 \\
\hline $\begin{array}{l}\text { Craft and related trades } \\
\text { workers }\end{array}$ & -0.39 & -0.53 & -0.58 & -0.55 \\
\hline $\begin{array}{l}\text { Plant and machine } \\
\text { operators and assemblers }\end{array}$ & -0.56 & -0.58 & -0.55 & -0.50 \\
\hline \multirow[t]{3}{*}{ Elementary occupations } & -0.50 & -0.57 & -0.46 & -0.43 \\
\hline & \multicolumn{4}{|c|}{ Correlation with occupational heterogeneity } \\
\hline & 1980 & 1990 & 2000 & 2010 \\
\hline Managers & -0.08 & -0.24 & -0.28 & -0.39 \\
\hline Professionals & -0.12 & -0.23 & -0.45 & -0.67 \\
\hline $\begin{array}{l}\text { Technicians and associate } \\
\text { professionals }\end{array}$ & 0.32 & 0.16 & 0.36 & 0.34 \\
\hline Clerical support workers & 0.23 & 0.36 & 0.34 & 0.38 \\
\hline Service and sales workers & -0.25 & -0.27 & 0.04 & 0.08 \\
\hline $\begin{array}{l}\text { Craft and related trades } \\
\text { workers }\end{array}$ & 0.41 & 0.46 & 0.17 & 0.42 \\
\hline $\begin{array}{l}\text { Plant and machine } \\
\text { operators and assemblers }\end{array}$ & -0.11 & 0.08 & 0.39 & 0.47 \\
\hline Elementary occupations & -0.05 & 0.19 & 0.26 & 0.31 \\
\hline
\end{tabular}

\subsubsection{Residential Segregation Between Economic Groups}

We next focus on the degree of segregation between economic groups, as measured by occupation categories. We assessed this by computing the index of dissimilarity between various groups in each of the decades of the study. The complete results are presented in Tables 19.2 and 19.3. We also visually present some results to illustrate the extent to which segregation between the most prestigious occupations (managers and professionals) and other occupation groups have changed over time. As shown in Fig. 19.4, these higher status occupations were most segregated from plant and machine operators in 1980 and 1990, but the level of segregation between these groups has not changed much over this time period.

On the other hand, the degree of segregation between these higher status occupation groups and elementary occupations has shown a steady increase over the study period, and since 2000 have shown the highest degree of segregation among the 


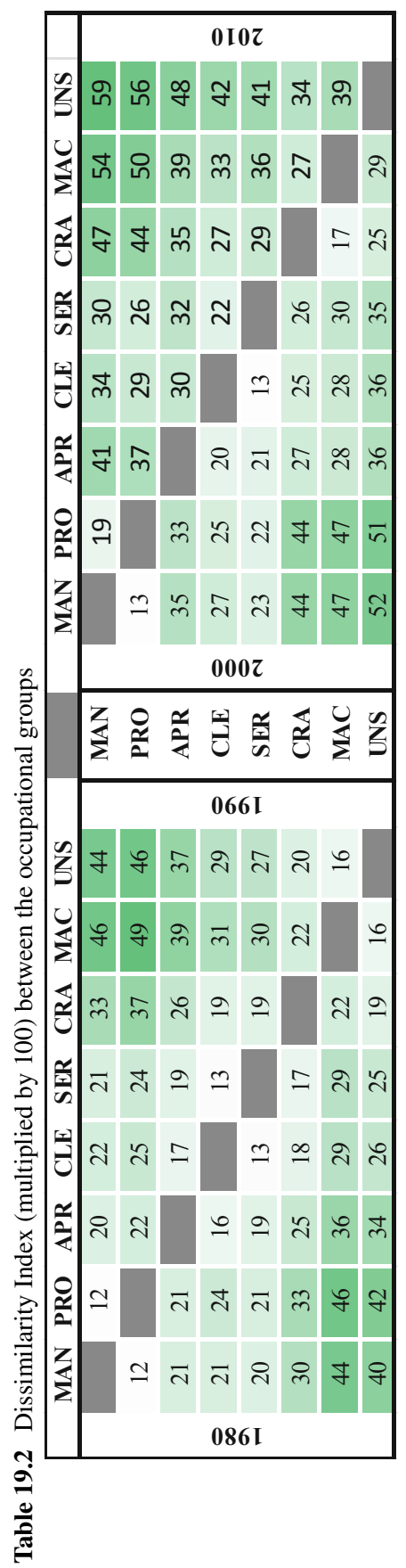


Table 19.3 Dissimilarity Index (multiplied by 100) between Top, Middle and Bottom groups

\begin{tabular}{|c|c|c|c|c|}
\hline & $\mathbf{1 9 8 0}$ & $\mathbf{1 9 9 0}$ & $\mathbf{2 0 0 0}$ & $\mathbf{2 0 1 0}$ \\
\hline TOP - MID & 21 & 21 & 25 & 29 \\
TOP - BOT & 29 & 31 & 34 & 36 \\
\hline MID - BOT & 15 & 16 & 15 & 20 \\
\hline
\end{tabular}

Los Angeles economic segregation

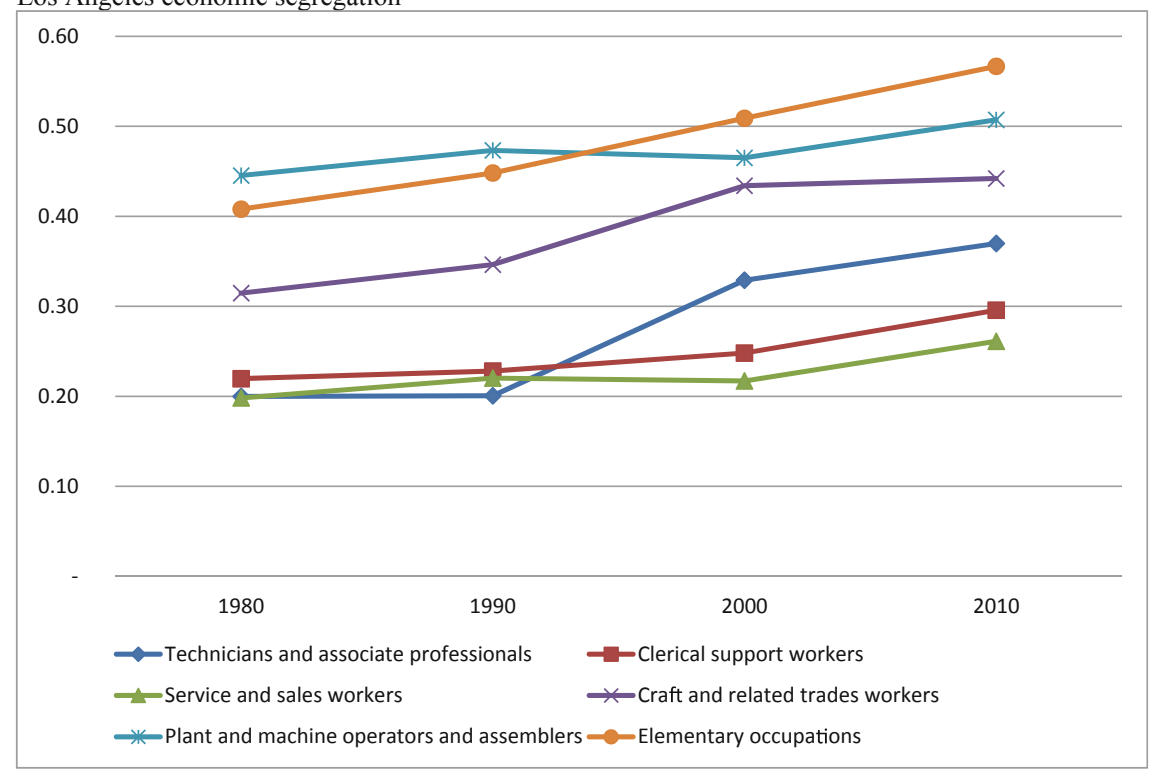

Fig. 19.4 Index of dissimilarity between managers/professionals and specific classes

groups shown in Fig. 19.1; the index of dissimilarity has increased from 0.41 to 0.57 over these 30 years. This finding is well illustrated in Fig. 19.5, juxtaposing the tract-level location quotients (LQ) of the higher status occupation groups and those of elementary occupations. Managers and professionals are concentrated in some affluent areas, including the northwestern parts of Los Angeles County and southern Orange County, where elementary occupations' LQ has remained extremely low. Figure 19.6 also highlights these locations in the region appearing largely stable over time, while some temporal changes are noticeable.

Other occupation groups have also shown an increasing trend of the dissimilarity index, suggesting that the overall level of occupational segregation has strengthened quite noticeably in the Los Angeles metropolitan region. For instance, whereas in 1980 and 1990 there were relatively low levels of segregation between these higher status occupations and technicians and associate professionals, this has jumped from 0.20 in 1980 to 0.37 in 2010. The lowest levels of segregation for these higher status occupations are with those in clerical support or sales and service occupations. 


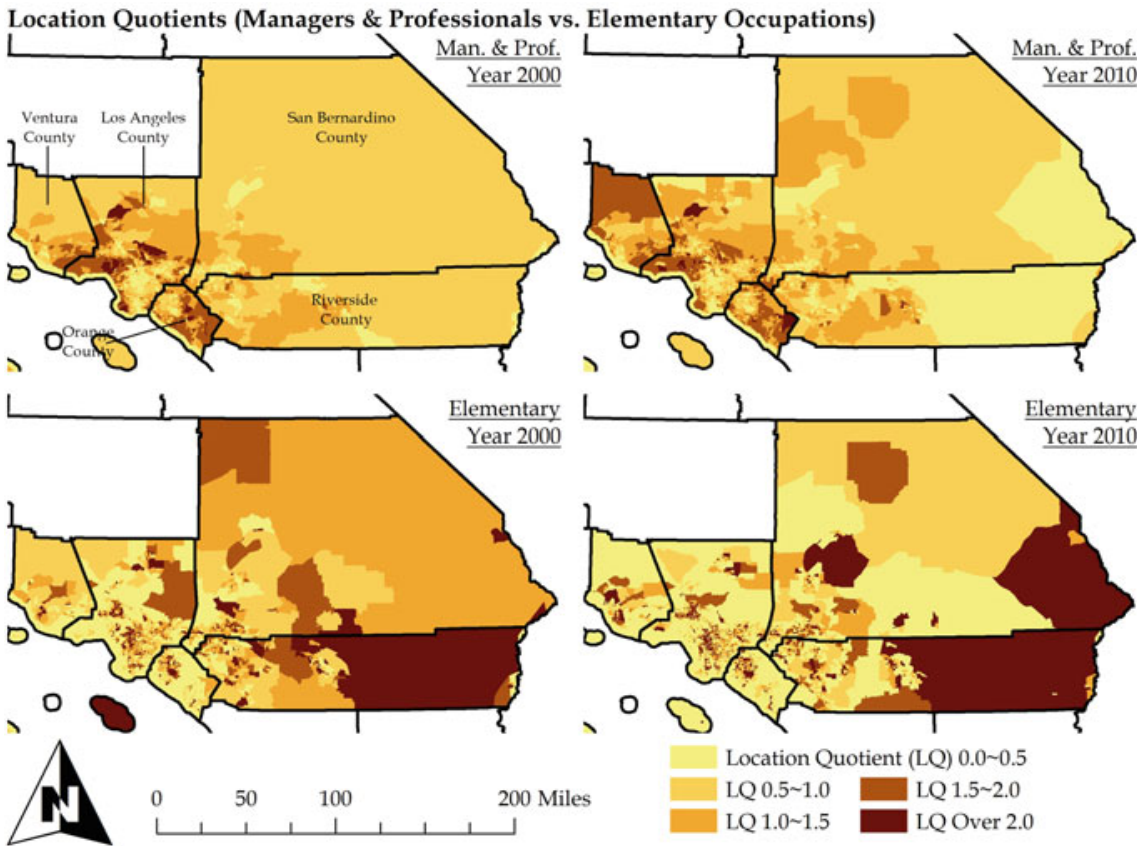

Fig. 19.5 Managers and professionals versus elementary occupations

We also explored the change over time in segregation between workers classified into high, middle, or low-status occupations. Following Marcinczak et al. (2015), we defined these as: high status is managers and professional occupations; middle status is technicians and associate professionals and clerical support workers; low status is service and sales workers, craft and related trades workers, plant and machine operators and assemblers, and elementary occupations. The segregation between the highest and lowest occupation workers has steadily increased over the study period, rising from 0.29 in 1980 to 0.36 in 2010 as seen in Table 19.3. The segregation between high and middle occupation workers has also risen since 1990, going from 0.21 in 1990 to 0.29 in 2010 . The level of segregation between middle and lowerstatus occupations has not increased as dramatically, as the segregation between these groups remained flat between 1980 and 2000, and has only risen in the last decade from 0.15 to 0.20 .

Finally, although we have seen a rise in occupational segregation in the region over this time period, there is less evidence of a rise in racial/ethnic segregation. We assessed this by computing the Theil index across tracts in each of the counties based on five racial/ethnic categories (Asian, Black, White, Latino, and other race). Whereas Los Angeles County has consistently experienced the highest racial/ethnic segregation in the region, the values have actually drifted downward over these thirty years (from 0.37 to 0.315). Riverside and San Bernardino counties have consistently had the lowest levels of racial/ethnic segregation over this period, with values around 


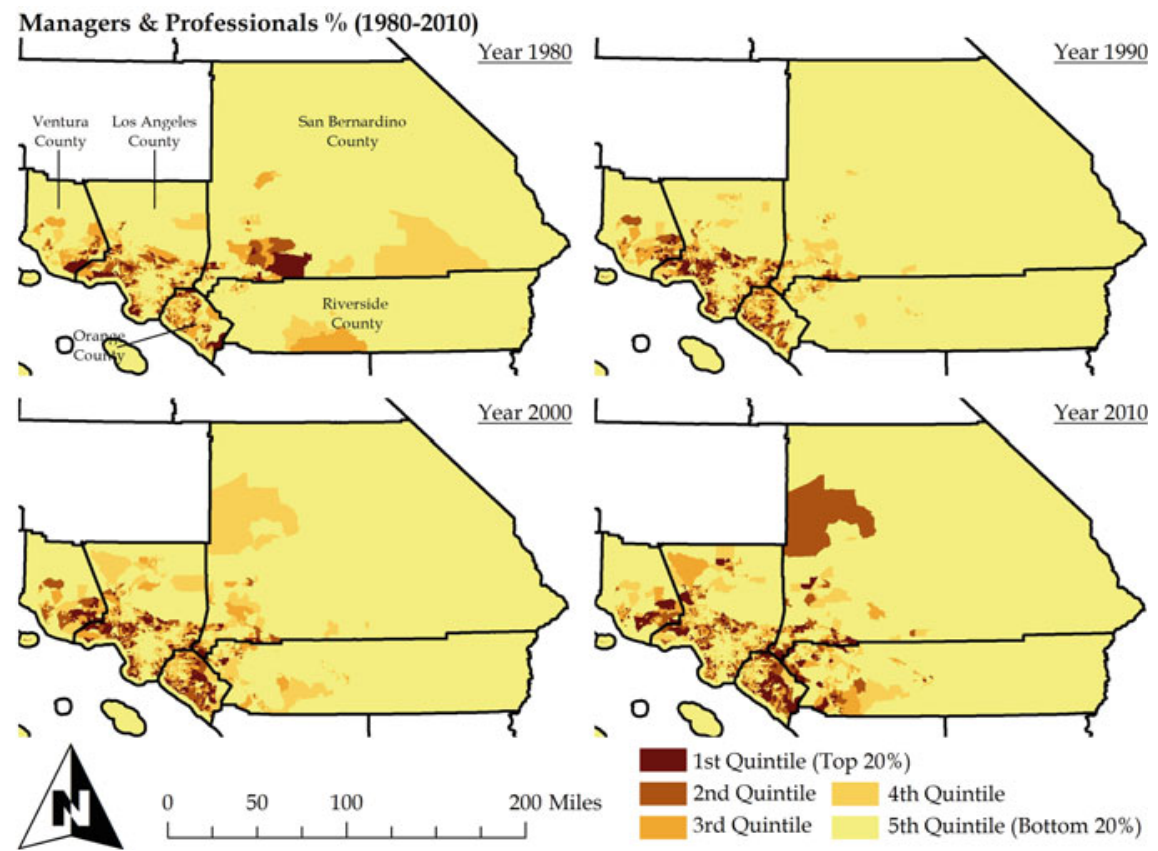

Fig. 19.6 Distribution of managers and professionals, 1980-2010

0.16. Ventura is slightly higher (0.22), although it has remained stable. Only Orange County has experienced a modest increase over the study period from 0.16 to 0.23 . Thus, the increasing occupational segregation in the region appears to not be related to racial/ethnic segregation processes.

\subsection{Conclusion}

This study has focused on how levels of inequality in the Los Angeles area have changed from 1980 to 2010 . Whereas we observed notable increases in inequality over the time period, as measured by the Gini coefficient based on household income levels, we also observed substantial changes in the region's occupation structure. The region has experienced a large increase in the proportion of professional workers over the study period. At the same time, there has been a large drop in the relative proportion of plant and machine operators. This pattern is consistent with the restructuring of jobs from blue collar towards white collar work, especially in this region.

Importantly, we also detected evidence of increasing residential segregation across the economic groups over time. Among others, we found that the highest status occupations (managers and professional workers) are becoming more spatially segregated from other occupations over the study period, while the rates of segregation increase 
varied by group and decade. There was also evidence that these highest status occupation workers tend to live in areas with the most economical resources to which other groups have limited access.

Admittedly, the traditional dissimilarity index and other metrics employed in this study would not allow us to capture the full extent and details of the segregation dynamics underway in the Los Angeles metropolitan region. It is also known that the census tracts used here, as done in numerous other studies, have a limited ability to represent the true neighbourhood boundaries in reality. There is also concern that the lower sampling rate of the ACS in 2010 can bias segregation estimates; indeed, studies have shown such an effect when measuring economic segregation based on binned income data (Reardon et al. 2018). However, the fact that our occupation categories are less extensive than the income bins (and therefore not as subject to small counts) suggests that our results may be less impacted by this issue. Also, other limitations would not invalidate the strong evidence of increasing occupational segregation patterns and should not undermine the implications of the evidence that deserves further attention.

How these patterns might change as Los Angeles County-the central county in the region-continues to build out its light rail public transportation system, remains to be seen. In the short-term, these new light rail lines seem to engender gentrification processes in the adjacent neighbourhoods. In the long-term, the question arises whether this public investment can change some of the current patterns observed in this more sprawling, car-centric, development. One can be optimistic about the future, given that there have been numerous state-level efforts to promote affordable housing provision in various locations, including transit-rich areas, but we should not underestimate the obstacles that will have to be overcome in order to make a meaningful difference in the next decades.

\section{References}

Blumenberg E, Manville M (2004) Beyond the spatial mismatch: welfare recipients and transportation policy. J Plann Lit 19:182-205

Byun P, Esparza AX (2005) A revisionist model of suburbanization and sprawl: The role of political fragmentation, growth control, and spillovers. J Plann Educ Res 24:252-264

Carruthers JI (2003) Growth at the fringe: the influence of political fragmentation in United States metropolitan areas. Papers Reg Sci 82:475-499

Chetty R, Grusky D, Hell M, Hendren N, Manduca R, Narang J (2017) The fading American dream: trends in absolute income mobility since 1940. Science 356:398-406

Hipp JR, Kane K, Kim JH (2017a) Jobs-housing balance in Egohoods in Southern California. Metropolitan Futures Initiative (MFI), Irvine, CA

Hipp JR, Kane K, Kim JH (2017b) Recipes for neighborhood development: a machine learning approach toward understanding the impact of mixing in neighborhoods. Landscape Urban Plann 164:1-12

Hipp JR, Kim JH, Basolo V (2014) Southern California regional progress report: 2014. Metropolitan Futures Initiative (MFI), Irvine, CA

Hogen-Esch T (2011) Fragmentation, fiscal federalism, and the ghost of Dillon's rule: municipal incorporation in Southern California, 1950-2010. Calif J Polit Policy 3:1-22 
Hu L (2015) Job accessibility of the poor in Los Angeles: has suburbanization affected spatial mismatch? J Am Plann Assoc 81:30-45

Kane K, Hipp JR, Kim JH (2018) Los Angeles employment concentration in the twenty-first century. Urban Stud 55:844-869

Kane K, Kim JH, Hipp JR (2016) Detecting job density over time. Metropolitan Futures Initiative (MFI), Irvine, CA

Kane K, Kim JH, Hipp JR (2017) What makes housing accessible to everyday destinations in Southern California. Metropolitan Futures Initiative (MFI), Irvine, CA

Kim JH, Hipp JR, Basolo V, Dillon HS (2018) Land use change dynamics in southern California: does geographic elasticity matter? J Plann Educ Res 38:39-53

Kim JH, Jurey N (2013) Local and regional governance structures: Fiscal, economic, equity, and environmental outcomes. J Plann Lit 28:111-123

Le Goix R (2005) Gated communities: Sprawl and social segregation in Southern California. Hous Stud 20:323-343

Levine N (1999) The effects of local growth controls on regional housing production and population redistribution in California. Urban Stud 36:2047-2068

Marcińczak S, Tammaru T, Novák J, Gentile M, Kovács Z, Temelová J, Valatka V, Kährik A, Szabó B (2015) Patterns of socioeconomic segregation in the capital cities of fast-track reforming postsocialist countries. Ann Assoc Am Geogr 105:183-202

McKenzie E (2003) Common-interest housing in the communities of tomorrow. Hous Policy Debate 14:203-234

Ong P, Blumenberg E (1998) Job access, commute and travel burden among welfare recipients. Urban Stud 35:77-93

Reardon SF, Bischoff K (2011) Income inequality and income segregation. Am J Sociol 116:10921153

Reardon SF, Bischoff K, Owens A, Townsend JB (2018) Has income segregation really increased? Bias and bias correction in sample-based segregation estimates. Demography 55:2129-2160

Sanchez TW, Lang RE, Dhavale DM (2005) Security versus status? A first look at the census's gated community data. J Plann Educ Res 24:281-291

Scarpa S (2016) Looking beyond the neighbourhood: income inequality and residential segregation in Swedish metropolitan areas, 1991-2010. Urban Geogr 37:963-984

Sommeiller E, Price M (2018) The new gilded age: Income inequality in the U.S. by state, metropolitan area, and county. Economic Policy Institute, Washington DC

Tong X, Kim JH (2019) Concentration or diffusion? Exploring the emerging spatial dynamics of poverty distribution in Southern California. Cities 85:15-24

Ulfarsson GF, Carruthers JI (2006) The cycle of fragmentation and sprawl: a conceptual framework and empirical model. Environ Plann B: Plann Des 33:767-788

Open Access This chapter is licensed under the terms of the Creative Commons Attribution 4.0 International License (http://creativecommons.org/licenses/by/4.0/), which permits use, sharing, adaptation, distribution and reproduction in any medium or format, as long as you give appropriate credit to the original author(s) and the source, provide a link to the Creative Commons license and indicate if changes were made.

The images or other third party material in this chapter are included in the chapter's Creative Commons license, unless indicated otherwise in a credit line to the material. If material is not included in the chapter's Creative Commons license and your intended use is not permitted by statutory regulation or exceeds the permitted use, you will need to obtain permission directly from the copyright holder.

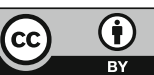

